\title{
Impact of Ex-Situ and In-Situ Cleans on the Performance of Bipolar Transistors With Low Thermal Budget In-Situ Phosphorus-Doped Polysilicon Emitter Contacts
}

\author{
Ahmad Ismat Abdul Rahim, Chris D. Marsh, Peter Ashburn, and G. R. Booker
}

\begin{abstract}
This paper investigates the effects of an in-situ hydrogen bake and an $e x$-situ hydroflouric acid (HF) etch prior to polysilicon deposition on the electrical characteristics of bipolar transistors fabricated with low thermal budget in-situ phosphorusdoped polysilicon emitter contacts. Emitter contact deposition in a UHV-compatible low pressure chemical vapor deposition (LPCVD) cluster tool is also compared with deposition in a LPCVD furnace. Transmission electron microscopy (TEM) and secondary ion mass spectroscopy (SIMS) are used to characterize the emitter contact material and the interface structure and a comparison is made with Gummel plots and emitter resistances on bipolar transistors. The SIMS results show that an in-situ hydrogen bake in a cluster tool gives an extremely low oxygen dose at the interface of $6.3 \times 10^{13} \mathrm{~cm}^{-2}$, compared with $7.7 \times$ $10^{14}$ and $2.9 \times 10^{15} \mathrm{~cm}^{-2}$ for an ex-situ $\mathrm{HF}$ etch and deposition in a cluster tool or a LPCVD furnace, respectively. TEM shows that the in-situ hydrogen bake results in single-crystal silicon with a high density of defects, including dislocations and twins. The ex-situ HF etch gives polycrystalline silicon for deposition in both a cluster tool and a LPCVD furnace. The single-crystal silicon emitter contact has an extremely low emitter resistance of $21 \Omega . \mu \mathrm{m}^{2}$ in spite of the high defect density and the light emitter anneal of $30 \mathrm{~s}$ at $900{ }^{\circ} \mathrm{C}$. This compares with emitter resistances of 151 and $260 \Omega . \mu \mathrm{m}^{2}$ for the polycrystalline silicon contacts produced using an ex-situ $\mathrm{HF}$ etch and deposition in a cluster tool or a LPCVD furnace, respectively. These values of emitter resistance correlate well with the interface oxygen doses and the structure of the interfacial oxide layer. The high defect density in the single-crystal silicon is considered to be due to the high concentration of phosphorus $\left(>5 \times 10^{19} \mathrm{~cm}^{-3}\right)$ in the as-deposited layers.
\end{abstract}

Index Terms-Bipolar transistor, cluster tool, in-situ doped polysilicon, polycrystalline silicon, polysilicon, polysilicon emitter.

\section{INTRODUCTION}

$\mathbf{P}$ OLYSILICON emitter contacts [1] have become a vital part of today's bipolar and BiCMOS technologies because they provide a means of realizing an exceptionally shallow

\footnotetext{
Manuscript received June 24, 1999; revised August 17, 2000. This work was supported by the EPSRC through the award of a research contract and the Universiti Sains Malaysia through the award of a studentship. The review of this paper was arranged by Editors P. Asbeck and T. Nakamura.

A. I. A. Rahim and P. Ashburn are with the Department of Electronics and Computer Science, University of Southampton, Southampton SO17 1BJ, U.K. (e-mail: pa@ecs.soton.ac.uk).

C. D. Marsh and G. R. Booker are with the Department of Materials, University of Oxford, Oxford OX1 3PH, U.K.

Publisher Item Identifier S 0018-9383(01)09061-X.
}

emitter/base junction while maintaining a reasonable peripheral emitter/base capacitance. In polysilicon emitter contacts, an interfacial oxide layer is invariably present at the polysilicon/ silicon interface, which has the advantage of increasing the current gain [2], [3] but the disadvantage of increasing the emitter resistance of the transistor [4]-[7]. A considerable amount of work has been published in the literature on the effects of the interfacial oxide on the base current [8]-[11] and emitter resistance [4]-[7], [12], [13] of polysilicon emitter contacts. It has been found that the nature of the interfacial oxide is significantly influenced by a number of factors, including the type of ex-situ clean (typically an HF etch) used prior to polysilicon deposition [9], [14], the polysilicon deposition conditions [15], [16], and the subsequent annealing conditions [8]. A common requirement in all the work mentioned above is the need to achieve a well controlled interfacial oxide that gives low values of emitter resistance.

The use of a cluster tool for polysilicon deposition is one approach that has been used to achieve good control over the interfacial oxide. Cluster tools are designed to integrate several process steps in one system, so in the context of polysilicon emitter contacts a cluster tool can be used to carry out an in-situ interface clean prior to the deposition of in-situ doped polysilicon [17]-[25]. Berthold et al. [23], using an ex-situ HF dip etch and reoxidation in a cluster tool, showed that the interfacial oxide can be varied in a controlled manner from $0.2-1.0 \mathrm{~nm}$. This approach allows the interfacial oxide thickness to be optimized to give an improved gain and an acceptable value of emitter resistance [17], [19]-[23]. For example, Decoutere et al. [19] and Simeon et al. [20] showed that an interfacial oxygen dose of $2.6 \times 10^{15} \mathrm{~cm}^{-2}$ (equivalent to a uniform layer of thickness $\approx 0.5 \mathrm{~nm}$, assuming that the oxide is stoichiometric $\mathrm{SiO}_{2}$ ) gave an emitter resistance of $170-200 \Omega \cdot \mu \mathrm{m}^{2}$ and at the same time a current gain enhancement by a factor of two. This was achieved by carrying out an in-situ HF vapor etch followed by dry reoxidation in a cluster tool. Similar results were obtained by Hendriks [17], who grew interfacial oxides with thicknesses of $0.5-1.0 \mathrm{~nm}$, and obtained an emitter resistance of $100 \Omega \cdot \mu \mathrm{m}^{2}$ and a gain improvement by a factor of two. Other authors have used an in-situ HF vapor etch [17]-[21] in a cluster tool and obtained emitter resistances of 90 [17], 74-80 [22] and 106 $\Omega \cdot \mu \mathrm{m}^{2}[19]$, [20]. However, for deep submicron polysilicon emitters, lower emitter resistance values are required. 
A related area of research where surface cleaning techniques are of paramount importance is low temperature epitaxy [26]-[32]. Two alternative approaches have been used to generate a clean surface prior to epitaxy. In the first approach, an ex-situ HF etch is used to give a hydrogen-passivated, hydrophobic silicon surface. This hydrogen passivated surface is air-stable and remains oxide-free for around $10 \mathrm{~min}$ [33]. Using this method, device quality $\mathrm{Si}$ and $\mathrm{SiGe}$ epi-layers were obtained at $550{ }^{\circ} \mathrm{C}$ or lower without employing any in-situ surface cleaning process. In the second approach, an in-situ hydrogen bake is used to desorb the surface oxide prior to growth [34]. The surface oxide is generally removed by thermal desorbtion at a temperature above $800{ }^{\circ} \mathrm{C}$ in hydrogen or above $950{ }^{\circ} \mathrm{C}$ in ultrahigh vacuum [34].

The use of a cluster tool for emitter contact deposition offers the prospect of achieving very low values of emitter resistance as a result of the clean growth environment and the ability to carry out an in-situ clean immediately prior to growth of the emitter contact material. However, to date, little has been published on the best combination of ex-situ and in-situ cleans needed to achieve this goal, particularly under conditions where low thermal budget emitter anneals are used. In this paper, a comparison is made of the effects of an ex-situ HF etch and an in-situ hydrogen bake emitter contact clean on the performance of bipolar transistors given low thermal budget emitter anneals. The deposited layers are in-situ doped with phosphorus rather than arsenic, because it has a higher diffusivity and hence, is potentially a better candidate for low thermal budget polysilicon emitters. A comparison is made between the in-situ phosphorus doped and conventional arsenic implanted emitter contacts. TEM images show that the in-situ hydrogen bake results in an emitter contact that is single-crystal silicon with a high density of defects, including dislocations and twins. Bipolar transistors fabricated using this high defect density silicon emitter contact have an emitter resistance as low as $21 \Omega . \mu \mathrm{m}^{2}$ even after a light emitter anneal of only $30 \mathrm{~s}$ at $900{ }^{\circ} \mathrm{C}$.

\section{EXPERIMENTAL PROCEDURE}

A very light emitter anneal of $30 \mathrm{~s}$ at $900{ }^{\circ} \mathrm{C}$ was chosen for this work in order to investigate the properties of low thermal budget polysilicon emitter contacts of the type that may be required in future deep submicron technologies or SiGe HBT technologies. This thermal budget is considerably lighter than that currently used for production polysilicon emitter contacts, where the emitter anneal is generally carried out at a temperature in the range $1000-1055^{\circ} \mathrm{C}$ [25], [35]-[39]. With a thermal budget as low as $30 \mathrm{~s}$ at $900^{\circ} \mathrm{C}$, it is difficult to obtain sufficient out-diffusion of dopant from the polysilicon to push the emitter/base depletion region away from the polysilicon/silicon interface. This is particularly problematic for the arsenic implanted control devices, because of the lower diffusion coefficient of arsenic than phosphorus. In order to facilitate the comparison of in-situ doped phosphorus emitters with ion implanted arsenic emitters, a low doped emitter was fabricated by ion implantation prior to emitter fabrication. The doping was chosen to be low enough to minimize Auger recombination, so that the low-doped emitter was transparent to minority carriers injected from the base [40]. This has the effect of making the base current very sensitive to the properties of the interface.

The starting material used for this work was (100) n on $n+$ material with an epitaxial resistivity of $0.5 \Omega \cdot \mathrm{cm}$. The base was fabricated by implanting $2.5 \times 10^{13} \mathrm{~cm}^{-2}$ boron at $80 \mathrm{keV}$ through an $80 \mathrm{~nm}$ thermal oxide layer and then annealing for $150 \mathrm{~min}$ at $1025^{\circ} \mathrm{C}$ in nitrogen. The low-doped emitter was used in all the devices and was formed by implanting $70 \mathrm{keV}, 5 \times 10^{14} \mathrm{~cm}^{-2}$ phosphorus through an $80 \mathrm{~nm}$ screen oxide and annealing for 120 minutes at $950{ }^{\circ} \mathrm{C}$ in nitrogen. SIMS profiles indicate that this process delivers a low-doped emitter with a width of $220 \mathrm{~nm}$ and a peak doping concentration of $1 \times 10^{19} \mathrm{~cm}^{-3}$.

Two interface cleans carried out prior to growth were investigated. The first was a clean which is commonly used in polysilicon emitter contacts, namely an ex-situ etch in 7:1 buffered $\mathrm{HF}$ for $15 \mathrm{~s}$. The second was a clean that is commonly used in low temperature epitaxy [26]-[34] and is a combined ex-situ and in-situ clean. The ex-situ clean comprised an RCA clean plus a 100:1 HF dip etch for half the time taken for the wafer to become hydrophobic. The in-situ clean consisted of a $5 \mathrm{~min}$ in-situ hydrogen bake at $900{ }^{\circ} \mathrm{C}$ in $100 \mathrm{sccm}$ of hydrogen at 1 Torr. The purpose of the hydrogen bake was to remove the interfacial oxide remaining after the RCA clean and the 100: $1 \mathrm{HF}$ dip etch. In-situ phosphorus doped polysilicon was deposited in a Thermo VG Semicon CV 200 System [41], which consists of two identical growth chambers linked by a load lock. The deposition time was $13 \mathrm{~min}$ and used a mixture of $100 \% \mathrm{SiH}_{4}$ and $0.01 \% \mathrm{PH}_{3}$ with flow rates of 100 and $50 \mathrm{sccm}$ at a temperature of $750{ }^{\circ} \mathrm{C}$ and a pressure of 1 torr.

For comparison purposes, a conventional arsenic implanted polysilicon emitter contact was also fabricated. This was given an ex-situ HF etch, and $200 \mathrm{~nm}$ of polysilicon was deposited in a conventional ASM LPCVD furnace in 25\%, $200 \mathrm{sccm}$ of $\mathrm{SiH}_{4}$ at $610{ }^{\circ} \mathrm{C}$ and 0.39 Torr. The polysilicon was doped by implanting a dose of $1 \times 10^{16} \mathrm{~cm}^{-2}$ arsenic at $45 \mathrm{keV}$. A low temperature oxide was deposited at $400{ }^{\circ} \mathrm{C}$ on all devices to prevent dopant loss during the $30 \mathrm{~s}$ emitter anneal at $900{ }^{\circ} \mathrm{C}$. An unpatterned in-situ phosphorus doped test wafer (i.e., not a device wafer) was also produced. This wafer was given a hydrogen bake, a 20 min deposition using the same growth conditions as the device wafers and was not given an emitter anneal.

Electrical characterization in the form of Gummel plots and emitter resistance measurements of the transistors were performed on a HP 4145 parameter analyzer attached to an HP 9133 personal computer. TEM and SIMS analysis were performed on the same wafers as the devices to determine the micro-structure and the phosphorus and oxygen profiles. The TEM analysis was carried out using $\langle 110\rangle$ cross-sections and $\langle 110\rangle$ on-axis images were obtained.

\section{RESULTS}

\section{A. Material and Interface Characterization}

Fig. 1 shows cross-section TEM images of the three types of sample after completion of device processing (i.e., after the emitter anneal). Fig. 1(a) shows the sample given an ex-situ HF etch prior to the deposition of in-situ phosphorus doped polysilicon. The layer is $350 \mathrm{~nm}$ thick and TEM selected area diffraction 

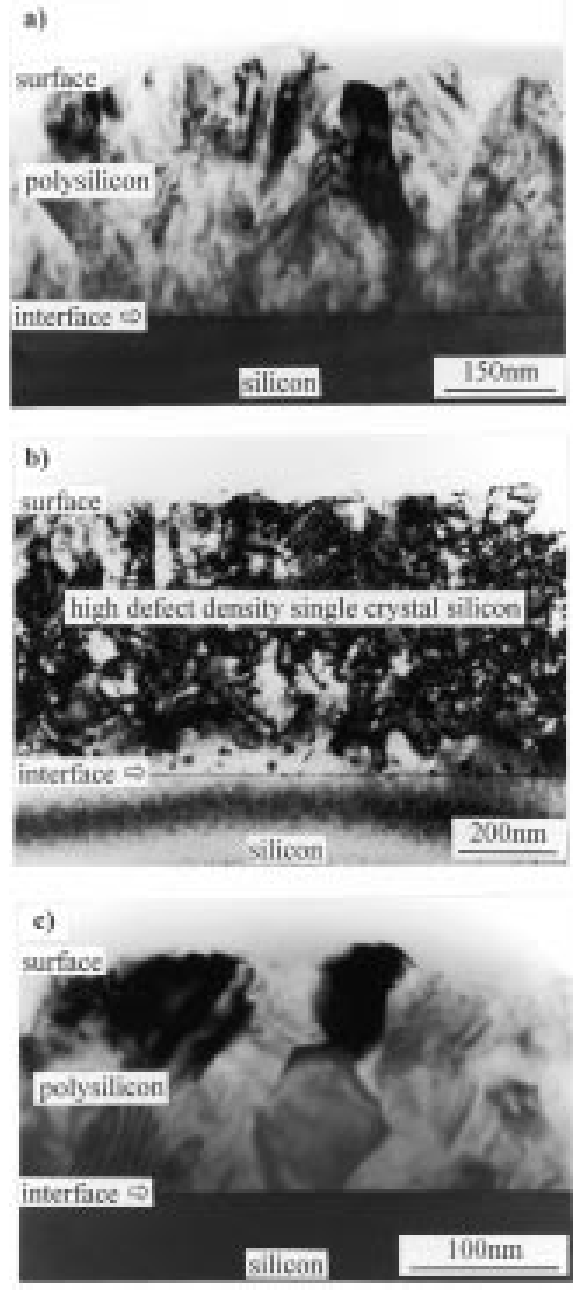

Fig. 1. Cross-section of TEM images of the device samples after the emitter anneal of $30 \mathrm{~s}$ at $900{ }^{\circ} \mathrm{C}$. (a) Ex-situ $\mathrm{HF}$ etch and in-situ phosphorus doped deposition. (b) In-situ hydrogen bake at $900{ }^{\circ} \mathrm{C}$ and in-situ phosphorus doped deposition. (c) Ex-situ HF etch and arsenic implanted LPCVD deposition.

patterns (not shown) show that it is polycrystalline. There is no significant epitaxial regrowth of the polysilicon, though there is some evidence of roughening at the polysilicon/silicon interface that is indicative of small holes in the interfacial oxide and local epitaxial regrowth. Fig. 1(b) shows the sample given an in-situ hydrogen bake prior to the deposition of in-situ phosphorus doped material. The layer is $570 \mathrm{~nm}$ thick and TEM selected area diffraction patterns (not shown) show that it is single-crystal silicon. The dark line in the micrograph is due to small discrete balls of interfacial oxide at the position of the original interface. The single-crystal layer contains different types of defects, including dislocations and twins. The defect density increases with distance from the interface up to a depth of $\sim 300 \mathrm{~nm}$, and between this depth and the surface the layer contains a high density of defects. Fig. 1(c) shows the arsenic implanted control device. This layer is $160 \mathrm{~nm}$ thick and TEM selected area diffraction patterns indicate that it is polycrystalline, as expected. The polysilicon/silicon interface is smooth, indicating that there is little or no interfacial oxide break up or epitaxial regrowth.

The in-situ phosphorus doped layers given the hydrogen bake are single-crystal silicon even after deposition. This is illustrated

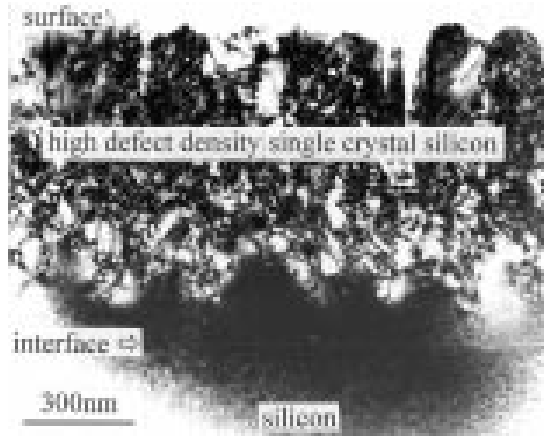

Fig. 2. Cross section TEM image of an unpatterned sample after deposition. The sample was given an in-situ hydrogen bake prior to in-situ phosphorusdoped deposition.

in Fig. 2, which shows a TEM image of an unpatterned wafer immediately after deposition. The wafer was given a hydrogen bake at $900{ }^{\circ} \mathrm{C}$ prior to deposition of the in-situ phosphorus doped layer and not given an emitter anneal. The layer is $850 \mathrm{~nm}$ thick and shows a 90-nm-wide region immediately above the interface that is relatively defect-free below a region that contains a high density of defects. The fact that the layer is single-crystal, i.e., epitaxial growth has occurred, suggests that the interfacial oxide was not continuous after the hydrogen bake. The thicker layer in this sample compared to that in Fig. 1(b) is due to the use of a longer growth time.

Fig. 3 shows SIMS profiles for layers after the emitter anneal. Fig. 3(a) shows the phosphorus SIMS profiles for the in-situ doped layers given either an in-situ hydrogen bake or an ex-situ $\mathrm{HF}$ etch. The phosphorus concentration is between 5 and $8 \times$ $10^{19} \mathrm{~cm}^{-3}$ for both layers over the majority of the thickness of the layer. However, for the layer given a hydrogen bake, the phosphorus concentration decreases to a value of $3.5 \times 10^{19}$ $\mathrm{cm}^{-3}$ immediately adjacent to the interface. Interface peaks occur for both layers, which are presumably due to segregated phosphorus at the original silicon surface. The ex-situ HF etch sample is $350 \mathrm{~nm}$ thick, and the in-situ hydrogen bake sample is $570 \mathrm{~nm}$ thick. The deposition time was the same for the two layers, so the difference in thickness suggests either a difference in incubation time for layers grown after an ex-situ HF etch and an in-situ hydrogen bake or a difference in growth rate for polysilicon and single-crystal silicon.

Fig. 3(b) shows oxygen SIMS profiles for the phosphorus in-situ doped layers and the arsenic implanted control layer. For the arsenic implanted control sample there is a large oxygen interface peak with an integrated dose of $2.9 \times 10^{15} / \mathrm{cm}^{2}$. For the in-situ phosphorus-doped layer given an HF etch, there is a similar peak with a dose of $7.7 \times 10^{14} / \mathrm{cm}^{2}$, i.e., $3.8 \times$ smaller. For the in-situ phosphorus-doped layer given a hydrogen bake, there is a similar peak with a dose of $6.3 \times 10^{13} / \mathrm{cm}^{2}$, i.e., a further $12 \times$ smaller. These three oxygen doses correspond to equivalent oxide layer thicknesses of $0.66,0.17$ and $0.014 \mathrm{~nm}$ respectively. The latter thickness for the in-situ phosphorus doped layer given a hydrogen bake corresponds to significantly less than a monolayer of silicon dioxide. Hence, the SIMS results also indicate that when the layer deposition commenced the interfacial oxide layer was discontinuous. 


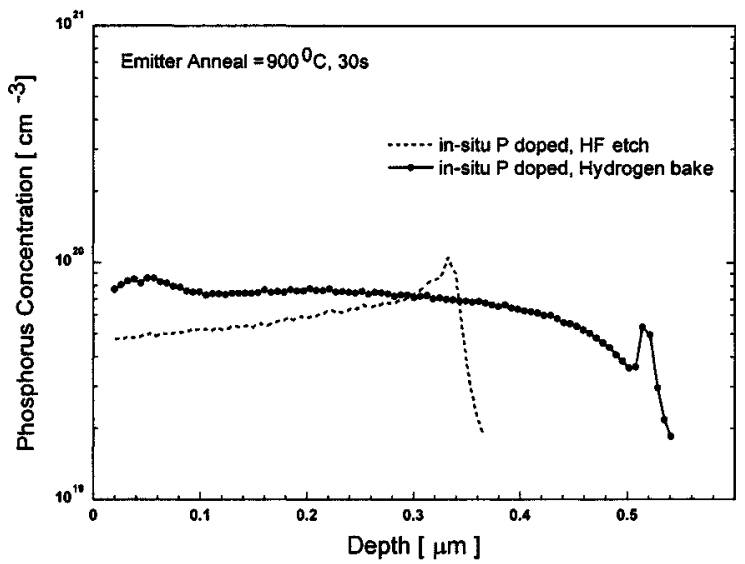

(a)

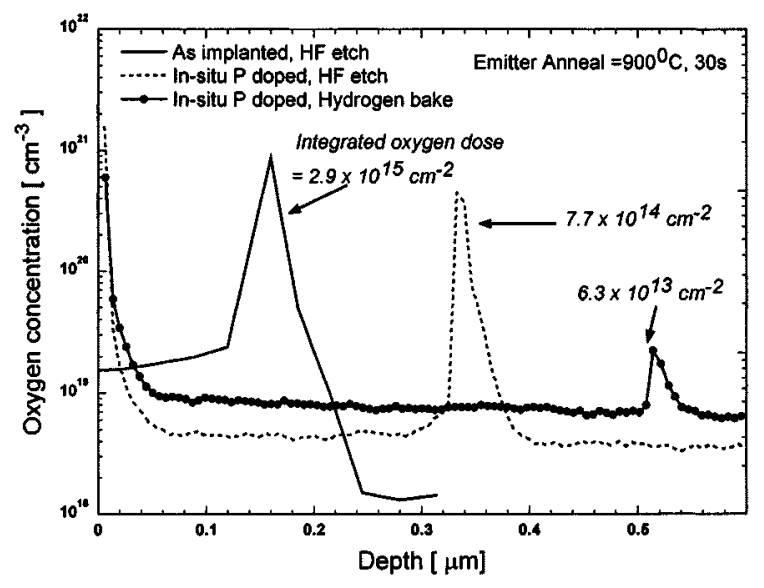

(b)

Fig. 3. SIMS profiles of layers produced using the different ex-situ and in-situ cleans and the different deposition systems: (a) phosphorus profiles and (b) oxygen profiles.

\section{B. Electrical Characterization}

Fig. 4 shows Gummel plots for transistors with in-situ phosphorus doped layers given an in-situ hydrogen bake or an ex-situ $\mathrm{HF}$ etch, and for comparison, a transistor with a conventional arsenic implanted polysilicon emitter. The lowest values of base current are obtained for the transistor with the arsenic implanted polysilicon emitter and the highest values for the transistor with the in-situ phosphorus doped emitter given the hydrogen bake. The difference in base current between these two types of transistor is a factor of 3.8 at a base/emitter voltage of $0.6 \mathrm{~V}$. A comparison of the two in-situ phosphorus doped transistors shows that the HF etch gives a lower base current than the hydrogen bake. The difference is a factor of 1.6 at a base/emitter voltage of $0.6 \mathrm{~V}$. A comparison of the Gummel plots with the oxygen SIMS profiles in Fig. 3(b) shows that a decreasing oxygen interface dose correlates with an increasing base current. A comparison with the TEM results in Fig. 1 indicates that the lowest base currents are obtained when the interfacial oxide is intact and the silicon is polycrystalline, and the highest base current when the interfacial oxide is broken up and the silicon is single-crystal. These results are consistent with a base current dominated by

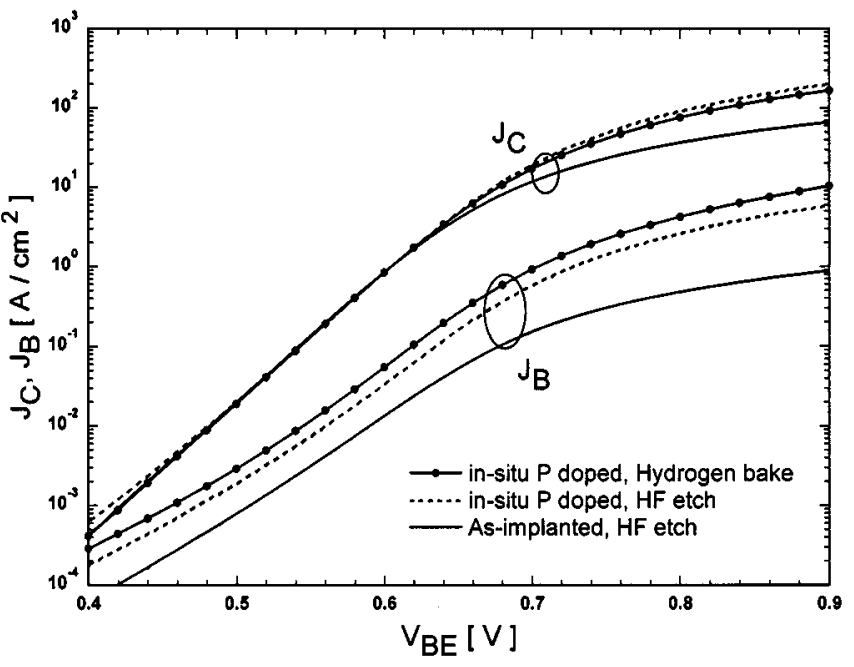

Fig. 4. Gummel plots for transistors produced using the different types of ex-situ and in-situ cleans and different deposition systems. $T=300 \mathrm{~K}, V_{C B}=$ $0 \mathrm{~V}$, and $A_{E}=80 \times 320 \mu \mathrm{m}^{2}$.

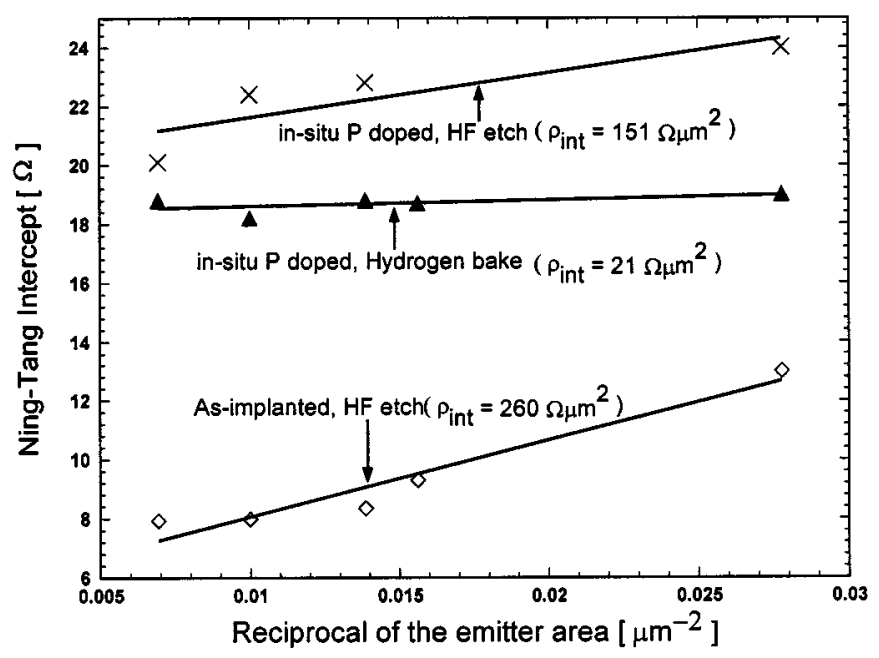

Fig. 5. Ning-Tang intercept [42] as a function of reciprocal emitter area for transistors produced using the different types of ex-situ and in-situ cleans and different deposition systems. The Ning-Tang intercept was measured on different geometry transistors and the slope of the graph gives the specific interface resistivity [43].

hole transport through the interfacial oxide layer when the oxide is intact and through holes in the oxide when the oxide is broken up [1].

Fig. 5 shows the determination of the specific interface resistivity $\rho_{\text {int }}$ on the three types of transistor using the NingTang method [42]. For each type of device, the emitter resistance was measured on devices with different geometries and the Ning-Tang intercept [42] plotted as a function of reciprocal emitter area. A linear regression was performed through the data points with the specific interface resistivity $\rho_{\text {int }}$ given by the slope of the linear fit [43]. It can be seen that $\rho_{\text {int }}=21 \Omega \cdot \mu \mathrm{m}^{2}$ for the in-situ phosphorus-doped transistors given the hydrogen bake and $\rho_{\text {int }}=151 \Omega \cdot \mu \mathrm{m}^{2}$ for the equivalent transistors given the HF etch. This compares with a value of $\rho_{i n t}=260 \Omega \cdot \mu \mathrm{m}^{2}$ for the transistor with a conventional arsenic implanted polysilicon emitter. A comparison with the oxygen SIMS profiles in 


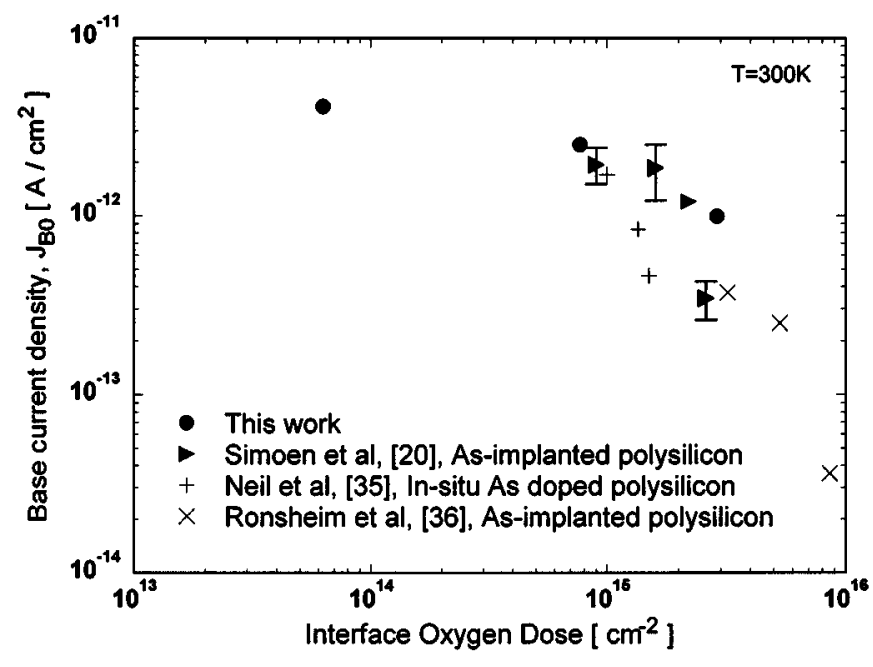

Fig. 6. Comparison of measured and literature values of base saturation current density as a function of interface oxygen dose. $T=300 \mathrm{~K}$.

Fig. 3(b) shows that a decreasing interface oxygen dose correlates with a decreasing emitter resistance. A comparison with the TEM results in Fig. 1 indicates that the highest emitter resistances are obtained when the interfacial oxide is intact and the deposited silicon is polycrystalline and the lowest emitter resistances when the interfacial oxide is broken up and the deposited silicon is single-crystal. This is consistent with a current dominated by electron transport through the interfacial oxide layer when the oxide is continuous and through holes in the oxide when the oxide is broken up [1].

\section{DISCUSSION}

The values of base saturation current density obtained in this work are compared with those reported in the literature in Fig. 6, where they are plotted against integrated interface oxygen dose. In cases where the literature data was taken at a temperature other than $300 \mathrm{~K}$, a correction has been applied using the equation $J_{B}=J_{B 0} \exp \left(q V_{B E} / k T\right)$, where the symbols have their usual meaning. Fig. 6 shows that the results obtained in this work are in reasonable agreement with those in the literature, although there is a wide spread in the data at interface oxygen doses between $1.3 \times 10^{15}$ and $3.1 \times 10^{15} \mathrm{~cm}^{-2}$. The data shows that the base saturation current density decreases with increasing interface oxygen dose, with the rate of decrease being slow for low oxygen doses and fast for high oxygen doses. The slow rate of decrease in base saturation current density corresponds to an interfacial oxide that is broken up, and the fast rate of decrease corresponds to an interfacial oxide that is continuous. This result indicates that the base saturation current is dominated by hole transport through the interfacial oxide layer [1]. When the interfacial oxide is broken up, there is little impediment to the flow of holes across the interface, so a high base saturation current is obtained. In contrast, when the interfacial oxide layer is continuous, there is a barrier to hole transport across the interface, and the base saturation current is limited by mechanisms such as tunneling [2] and thermionic emission [44].

Fig. 7 compares the interface oxygen doses obtained in this work for the different ex-situ and in-situ cleans with those re-

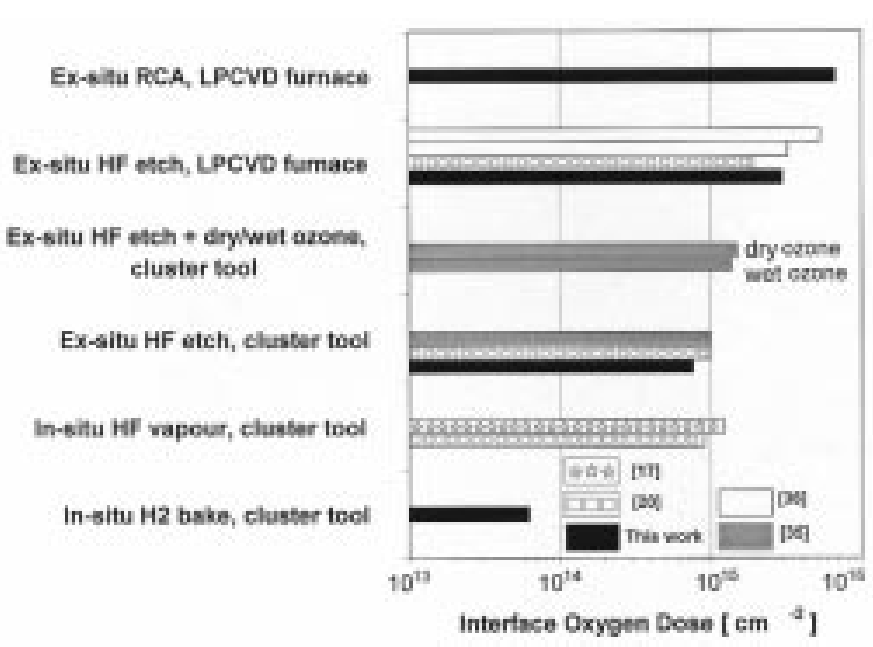

Fig. 7. Comparison of measured and literature values of interface oxygen dose for different ex-situ and in-situ cleans.

ported in the literature [17], [20], [35], [36]. In general, this figure shows that the cluster tool delivers lower values of oxygen dose than the LPCVD furnace, by a factor of typically three. Similar results have been reported by Simeon et al. [20], where it was found that the cluster tool produces typically a factor of 1.9 lower values of oxygen dose than the LPCVD furnace. For the $e x$-situ HF etch followed by polysilicon deposition in the LPCVD furnace, the interface oxygen dose of $3 \times 10^{15} \mathrm{~cm}^{-2}$ obtained in this work is in the middle of the reported range of 2 to $5 \times 10^{15} \mathrm{~cm}^{-2}$. For the HF dip followed by polysilicon deposition in the cluster tool, our interface oxygen dose of $7.7 \times 10^{14}$ $\mathrm{cm}^{-2}$ is at the bottom of the range of reported values, but nevertheless close to the reported values of $1.0 \times 10^{15} \mathrm{~cm}^{-2}$. The interface oxygen doses for an in-situ HF vapor etch in a cluster tool are similar to those for an ex-situ HF dip etch. This result indicates that the wafer transfer from the ex-situ HF etch to the cluster tool is sufficiently rapid to avoid the growth of additional interfacial oxide. This conclusion is consistent with the work of Meyerson et al. [33] who showed that the hydrogen passivated surface produced by an HF dip etch was stable in air for 10 minutes. For the hydrogen bake, our interface oxygen dose of $6.3 \times$ $10^{13} \mathrm{~cm}^{-2}$ is $14.3 \times$ lower than the lowest value of Simeon $e t$ al. [20]. This result demonstrates the effectiveness of the hydrogen bake for eliminating the interfacial oxide. Sun et al. [45] have also reported the use of an in-situ hydrogen bake prior to selective deposition of the polysilicon emitter, but no value of interface oxygen dose was given. For completeness, Fig. 7 also shows the interface oxygen doses for an ex-situ RCA clean performed in this work and an in-situ dry/wet ozone clean reported in the literature [35]. The latter has a higher interface oxygen dose than the HF etch, but was reported to have the advantages of removing hydrocarbon residues from the silicon surface and of stabilizing the interfacial oxide with time [35].

Fig. 8 compares the values of emitter resistance obtained in this work with those reported in the literature. The values of emitter resistance taken from the literature have been converted into units of $\Omega \cdot \mu \mathrm{m}^{2}$ using the quoted values of emitter area [17], [20]. For the devices (in this work) given an ex-situ HF etch (with interface oxygen doses of $7.7 \times 10^{14}$ using a cluster tool and 3 


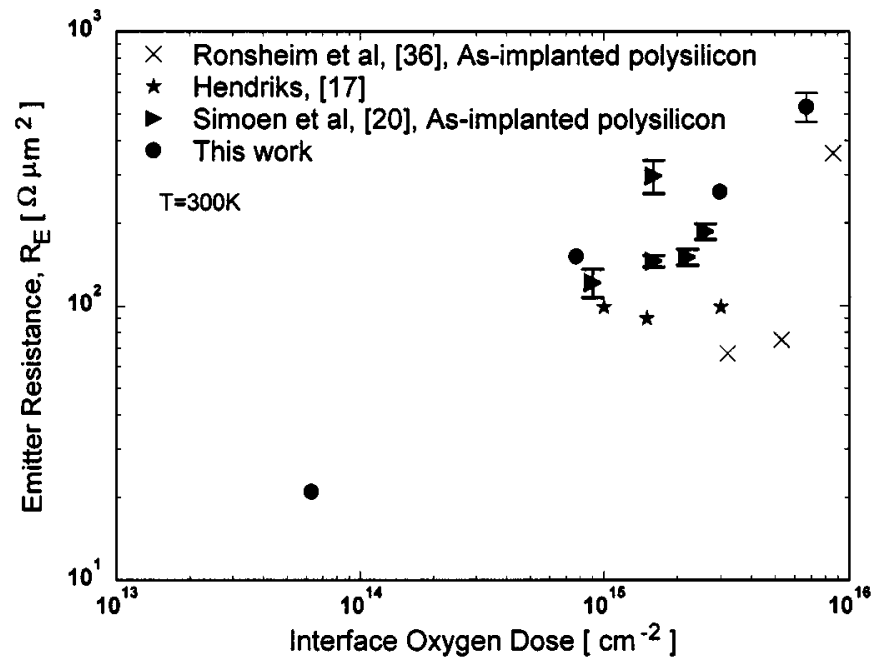

Fig. 8. Comparison of measured and literature values of emitter resistance as a function of interface oxygen dose.

$\times 10^{15} \mathrm{~cm}^{-2}$ using a LPCVD furnace), the values of emitter resistance are broadly similar to the values in the literature, though there is a large spread in the literature data. In spite of the large spread in emitter resistance values, it can be seen that the in-situ hydrogen bake gives a value of emitter resistance that is a factor of three lower than the lowest value reported in the literature. This result clearly demonstrates that the in-situ hydrogen bake gives extremely low values of emitter resistance. Sun et al. [45] have also used an in-situ hydrogen bake prior to the selective deposition of undoped polysilicon. The resulting polysilicon emitter bipolar transistors had emitter resistance values of less than $30 \Omega \cdot \mu \mathrm{m}^{2}$. This is in good agreement with the value of $21 \Omega \cdot \mu \mathrm{m}^{2}$ obtained in this work. In contrast with our results, Sun et al. [45] reported that the material was polycrystalline after deposition. This may be due to the fact that the layer was undoped or to the use of a $\mathrm{H}_{2} / \mathrm{HCl} / \mathrm{SiH}_{2} \mathrm{Cl}_{2}$ gas mixture, rather than the $\mathrm{H}_{2} / \mathrm{SiH}_{4} / \mathrm{PH}_{3}$ gas mixture used in this work.

The TEM image in Fig. 2 shows that the in-situ phosphorusdoped material given a hydrogen bake was single-crystal after growth with a high density of defects, but the silicon is relatively defect free in a 50-nm-thick region immediately above the interface. A comparison with the phosphorus SIMS profile in Fig. 3(a) shows that the phosphorus concentration decreases from about $5 \times 10^{19} \mathrm{~cm}^{-3}$ to $3.5 \times 10^{19} \mathrm{~cm}^{-3}$ over a distance of $50 \mathrm{~nm}$ above the interface. This result suggests that the high phosphorus concentration may be responsible for the high density of defects in the top part of the silicon layer, with the decrease in phosphorus concentration adjacent to the interface the reason for the lower defect density in this region. SIMS measurements on silicon layers with high phosphorus concentrations tend to confirm this explanation. For example, in layers with a uniform phosphorus concentration above $1 \times 10^{20}$ $\mathrm{cm}^{-3}$, the high density of defects extends all the way from the surface to the interface. The defects might result from misfit due to the smaller tetragonal radius of phosphorus than silicon [46]. High concentrations of phosphorus in silicon are well known to produce defects, for example dislocation networks in emitters implanted with a high dose of phosphorus [47]. Further work is underway to confirm the origins of the defects.

\section{CONCLUSIONS}

A study has been made of the effects of an ex-situ HF etch and an in-situ hydrogen bake on the emitter resistance and base current of low thermal budget, in-situ phosphorus-doped polysilicon emitter contacts for bipolar transistors. SIMS measurements have shown that an in-situ hydrogen bake in a cluster tool gives a very low interface oxygen dose of $6.3 \times 10^{13} \mathrm{~cm}^{-2}$, while an ex-situ HF etch gives a dose of either $7.7 \times 10^{14} \mathrm{~cm}^{-2}$ when the deposition is performed in a cluster tool or $2.9 \times 10^{15} \mathrm{~cm}^{-2}$ when it is performed in a LPCVD furnace. TEM shows that the in-situ hydrogen bake results in a material that is single-crystal silicon with a high density of defects, including dislocations and twins. Bipolar transistors fabricated using this high defect density silicon emitter contact have an emitter resistance as low as $21 \Omega \cdot \mu \mathrm{m}^{2}$ even after a light emitter anneal of $30 \mathrm{~s}$ at $900^{\circ} \mathrm{C}$. This is a factor of $7.2 \times$ lower than the emitter resistance obtained for cluster tool deposition after an ex-situ HF etch and $12.4 \times$ lower than that obtained for LPCVD furnace deposition after an $e x$-situ HF etch. The lower value of emitter resistance correlates with an increased base current by a factor of 3.8 for the two extreme cases. The high concentration of phosphorus in the deposited layers is considered to be the cause of the high defect density. In general, the very low value of emitter resistance obtained with the high defect density single-crystal silicon emitter contact suggests that this material could prove useful in future deep submicron Si bipolar or SiGe HBT technologies where the thermal budget is severely constrained.

\section{REFERENCES}

[1] I. R. C. Post, P. Ashburn, and G. Wolstenholme, "Polysilicon emitters for bipolar transistors: A review and re-evaluation of theory and experiment," IEEE Trans. Electron Devices, vol. 39, pp. 1717-1731, July 1992.

[2] H. C. De Graff and J. G. De Groot, "The SIS tunnel emitter: A theory for emitters with thin interfacial layers," IEEE Trans. Electron Devices, vol. ED-26, pp. 1771-1776, 1979.

[3] P. Ashburn and B. Soerowirdjo, "Comparison of experimental and theoretical results on polysilicon emitter bipolar transistors," IEEE Trans. Electron. Devices, vol. ED-31, pp. 853-860, 1984.

[4] T. H. Ning and R. D. Isaac, "Effect of emitter contact on current gain of silicon bipolar devices," in IEDM Tech. Dig., vol. 26, 1979, pp. 473-476.

[5] E. F. Chor, P. Ashburn, and A. Brunnschweiler, "Emitter resistance of arsenic- and phosphorus-doped polysilicon emitter transistors," IEEE Electron Device Lett., vol. EDL-6, pp. 516-518, 1985.

[6] P. A. Potyraj and D. W. Greve, "Emitter resistance in polysilicon emitters and the influence of interfacial oxides," in Proc. BCTM Tech. Dig., Minneapolis, MN, 1987, pp. 82-85.

[7] E. Crabbe, S. Swirhun, J. Del Alamo, F. F. W. Pease, and R. M. Swanson, "Majority and minority carrier transport in polysilicon emitter contacts," in IEDM Tech. Dig., Jan. 1986, pp. 28-31.

[8] G. L. Patton, J. C. Bravman, and J. D. Plummer, "Physics, technology and modeling of polysilicon contacts for VLSI bipolar transistors," IEEE Trans. Electron Devices, vol. ED-33, pp. 1754-1768, 1986.

[9] P. A. Potyraj, D. Chen, M. K. Hatalis, and D. W. Greve, "Interfacial oxides, grain size and hydrogen passivation effects on polysilicon," IEEE Trans. Electron Devices, vol. ED-26, p. 1771, 1979.

[10] P. Ashburn, D. J. Roulston, and C. R. Selvakumar, "Comparison of experimental and computed results on arsenic- and phosphorus-doped polysilicon emitter bipolar transistors," IEEE Trans. Electron Devices, vol. ED-34, pp. 1346-1353, 1987.

[11] K. Sagara, T. Nakamura, Y. Tamaki, and T. Shiba, "The effect of thin interfacial oxide on the electrical characteristics of silicon bipolar devices," IEEE Trans. Electron Devices, vol. ED-34, pp. 2286-2290, 1987.

[12] J. M. C. Stork, M. Arienzo, and C. Y. Wong, "Correlation between the diffusive and electrical barrier properties of the interface in polysilicon contacted n+-p junctions," IEEE Trans. Electron Devices, vol. ED-32, pp. 1766-1770, 1985. 
[13] J. S. Hamel, D. J. Roulston, C. R. Selvakumar, and G. R. Booker, "Twodimensional analysis of emitter resistance in the presence of interfacial oxide breakup in polysilicon emitter bipolar transistors," IEEE Trans. Electron Devices, vol. 39, pp. 2139-2146, 1992.

[14] G. R. Wolstenholme, N. Jorgenson, P. Ashburn, and G. R. Booker, "An investigation of the thermal stability of the interfacial oxide in polycrystalline silicon emitter bipolar transistors by comparing device results with high-resolution electron microscopy observations," J. Appl. Phys., vol. 61, pp. 225-233, 1987

[15] D. J. Doyle, J. D. Barrett, W. A. Lane, M. O'Neill, D. Bain, R. Baker, and P. J. Mole, "Comparison of bipolar npn polysilicon emitter interface formation at three different manufacturing sites," IEEE Trans. Semiconduct. Manufact., vol. 5, pp. 241-247, 1992.

[16] N. S. Parekh, R. V. Taylor, and D. O. Massetti, "A simple method to control bipolar polysilicon emitter interfacial oxide," J. Electrochem. Soc., vol. 141, pp. 3167-3172, 1994.

[17] M. Hendriks, "Interface engineering in silicon semiconductor processing using a vacuum cluster tool," Microelectron. Eng., vol. 25, pp. 185-200, 1994

[18] —, "Poly-gate structures manufactured in a cluster tool," Appl. Surface Sci., vol. 70/71, pp. 619-623, 1993.

[19] S. Decoutere, A. Curthbertson, R. Wilhelm, W. Vandervorst, and L. Deferm, "Engineering of the polysilicon emitter interfacial layer using low temperature thermal re-oxidation in an LPCVD cluster tool," in Proc. Eur. Solid-State Device Res. Conf., The Hague, The Netherlands, 1995, pp. 429-432.

[20] S. Simeon, S. Decoutere, A. Cuthbertson, C. L. Claeys, and L. Deferm, "Impact of polysilicon emitter interfacial layer engineering on the $1 / \mathrm{f}$ noise of bipolar transistors," IEEE Trans. Electron Devices, vol. 43, pp. 2261-2268, Dec. 1996.

[21] C. J. Werkhoven, J. E. M. Westendorp, F. Huusen, and E. H. A. Granneman, "Poly-emitter device manufacturing in a cluster tool," Semiconduct. Int., pp. 416-419, 228-230, 1991.

[22] R. H. Reuss, C. Workhoven, E. Granneman, and M. Hendriks, "Application of a cluster tool for interface engineering of polysilicon emitters," in Proc. BCTM Tech. Dig., Minneapolis, MN, 1993, pp. 49-51.

[23] A. M. Berthold, J. G. M. Mulder, A. V. Felde, L. F. T. Kwakman, I. Weitzel, H. V. Philipsborn, and H. Klose, "Controlled sub-nm oxide growth and its application to high speed bipolar poly-emitter transistors," in Eur. Solid-State Device Res. Conf., 1995, pp. 51-54.

[24] T. Hashimoto, T. Kumauchi, T. Jinbo, K. Watanabe, E. Toshida, H. Miura, T. Shiba, and Y. Tamaki, "Interface controlled IDP process technology for $0.3 \mu \mathrm{m}$ high-speed bipolar poly-emitter transistors," in Proc. BCTM Tech. Dig., Minneapolis, MN, 1996, pp. 181-184.

[25] D. Bensahel, Y. Campidelli, C. Harnendez, F. Martin, I. Sagnes, and D. J. Meyer, "Single-wafer processing of in situ-doped polycrystalline $\mathrm{Si}$ and $\mathrm{Si}_{1-x} \mathrm{Ge}_{x}$," Solid-State Technol., pp. S5-S10, March 1998.

[26] J. M. Bonar and G. J. Parker, "The epitaxy quality of silicon grown by LPCVD as a function of ex-situ wafer preparation," Inst. Phys. Conf. Series, no. 134, pp. 403-406, April 1993.

[27] A. J. Pidduck, R. Jackson, D. J. Robbins, W. Y. Leong, and M. Wheeler, "Optimising hydrophilic wafer cleaning for silicon epitaxy," J. Electrochem. Soc., vol. 92, no. 12, p. 453, 1992.

[28] C. Galewski, J. Lou, and W. Oldham, "Silicon wafer preparation for low temperature selective epitaxial growth," IEEE Trans. Semiconduct. Manufact., vol. 3, pp. 93-97, Aug. 1990.

[29] J. Lou and W. G. Oldham, "The surface morphology of selectively grown epitaxial silicon," J. Appl. Phys., vol. 70, no. 2, pp. 685-682, 1991.

[30] W. Kern and D. A. Puotinen, "Cleaning solutions based on hydrogen peroxide for use in silicon semiconductor technology," RCA Rev., vol. 39, pp. 1711-1716, 1992

[31] A. Ishizaka and Y. Shiraki, "Low temperature surface cleaning of silicon and its application to silicon MBE," J. Electrochem. Soc., vol. 133, pp. 666-671, Apr. 1986

[32] P. E. Thompson, M. E. Twigg, D. J. Godbey, and K. D. Horbart, "Low temperature cleaning processes for Si molecular beam epitaxy," J. Vac. Sci. Technol. B, vol. 11, no. 3, p. 1077, 1993.

[33] B. S. Meyerson, F. J. Himpsel, and K. J. Uram, "Bistable conditions for low temperature silicon epitaxy," Appl. Phys. Lett., vol. 57, p. 1034, 1990.

[34] T. O. Sedgwick and P. D. Agnello, "Atmospheric pressure chemical vapor deposition of $\mathrm{Si}$ and SiGe at low temperatures," J. Vac. Sci. Technol., vol. A10, p. 1913, 1992.

[35] S. Neil, C. Harnendez, R. Pantel, I. Sagnes, M. Berenguer, J. Kirtsch, A. Monroy, A. Chantre, and G. Vincent, "An investigation of polysilicon emitter bipolar transistors with an ozonized polysilicon/monosilicon interface," in Proc. 27th Eur. Solid-State Device Res. Conf., 1997, pp. $416-419$.
[36] P. A. Ronsheim, B. Cunningham, and M. D. Dupuis, "Characterization of polycrystalline silicon-single-crystal silicon interfaces and correlation to bipolar transistor device data," J. Appl. Phys., vol. 69, pp. 495-498, 1991.

[37] C. Y. Chang and S. M. Sze, ULSI Technology. New York: McGrawHill, 1996, p. 501.

[38] S. Neil, O. Rozeau, L. Ailloud, C. Harnandez, P. Llinares, M. Guillermet, J. Kirtsch, A. Monroy, J. de Pontcharra, G. Auvert, B. Blanchard, M. Mouis, G. Vincent, and A. Chantre, "A $54 \mathrm{GHz} f_{\max }$ implanted base $0.35 \mu \mathrm{m}$ single-polysilicon bipolar technology," in IEDM Tech. Dig., 1997, pp. 807-810.

[39] J. de Pontcharra, E. Behouche, L. Ailloud, D. Thomas, L. Vendrame, T. Gravier, and A. Chantre, "A $30 \mathrm{GHz} f_{T}$ quasiself-aligned single-poly bipolar technology," IEEE Trans. Electron Devices, vol. 44, pp. 2091-2097, Nov. 1997.

[40] N. E. Moiseiwitsch and P. Ashburn, "Optimization of $\mathrm{BF}_{2}$ implanted pnp polysilicon emitter bipolar transistors using rapid thermal annealing," in Proc. 23rd Eur. Solid-State Device Res. Conf., Grenoble, France, 1993, pp. $215-218$

[41] "Mobius: A new UHV compatible LPCVD," European Semiconduct., vol. 20, p. 9, 1998.

[42] T. H. Ning and D. D. Tang, "Method for determining the emitter and base series resistance of bipolar transistors," IEEE Trans. Electron Devices, vol. ED-31, pp. 409-412, 1984.

[43] G. R. Wolstenholme, P. Ashburn, N. Jorgenson, D. Gold, and G. R. Booker, "Measurement and modeling of the emitter resistance of polysilicon emitters," in Proc. BCTM Tech. Dig., Minneapolis, MN, 1988, pp. $55-58$.

[44] C. C. Ng and E. S. Yang, "A thermionic-diffusion model of polysilicon emitter," in IEDM Tech. Dig., Jan. 1986, pp. 32-35.

[45] S. W. Sun, D. Denning, J. D. Hayden, M. Woo, J. T. Fitch, and V. Kaushik, "A nonrecessed-base, self-aligned bipolar structure with selectively deposited polysilicon emitter," IEEE Trans. Electron Devices, vol. 39, pp. 1711-1716, July 1992

[46] C. Hill, "Private communication," GEC Marconi Mater. Technol., Caswell, Northants, U.K

[47] C. J. Bull, P. Ashburn, G. R. Booker, and K. H. Nicholas, "Effects of dislocations in silicon transistors with implanted emitters," Solid-State Electron., vol. 22, p. 95, 1979

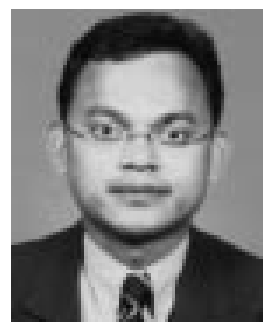

Ahmad Ismat Abdul Rahim was born in Penang, Malaysia, in 1971. He received the B.Eng. (honors) degree in electrical engineering in 1994, the M.Sc. degree in microelectronics systems design in 1996, and the Ph.D. degree in 1999, all from the University of Southampton, Southampton, U.K., perfroming his dissertation on the study of in-situ doped polysilicon emitters for applications in deep submicron BiCMOS and $\mathrm{SiGe}$ technologies.

He was in the Device Group of the Microelectronics Laboratory, MIMOS Berhad, Malaysia, where he was involved in the development of deep submicron CMOS and SiGe bipolar technology. Currently, he is with Malaysia Microelectronics Solutions Sdn. Bhd. (My-MS), working on the development of nonvolatile memory products.

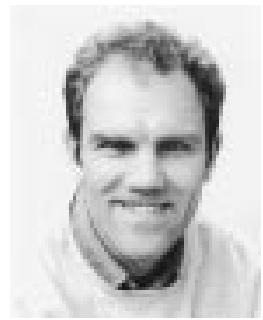

Chris D. Marsh received the B.Sc. degree in applied physics and electronics from the University of Lancaster, Lancaster, U.K., in 1983, and the D.Phil. degree in materials science from the University of Oxford, Oxford, U.K., in 1993.

In 1990, he became a Research Fellow in the Materials Department, University of Oxford. Prior to this, he was a Visiting Researcher at Hitachi's Central Research Laboratory, Japan. His research interests are in the microstructure of silicon-based materials for applications in microelectronics, in particular, the relationship between the microstructure, processing methods and electrical properties, and the application of transmission electron microscopy techniques to the study of the microstructure. He has authored more than 50 papers in the aforementioned areas.

Dr. Marsh is a Chartered Physicist and a member of the U.K. Institute of Physics. 


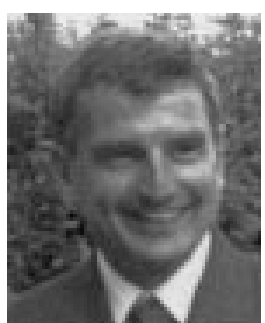

Peter Ashburn was born in Rotherham, U.K., in 1950. He received the B.Sc. degree in electrical and electronic engineering in 1971 and the Ph.D. degree in 1974, both from the University of Leeds, Leeds, U.K., performing his dissertation on experimental and theoretical study of radiation damage in silicon p-n junctions.

In 1974, he joined the Technical Staff of Philips Research Laboratories, Redhill, and worked initially on ion-implanted integrated circuit bipolar transistors and then on electron lithography for submicron integrated circuits. In 1978, he joined the Academic Staff of the Department of Electronics and Computer Science, University of Southampton, Southampton, U.K., as a Lecturer, where he is currently the holder of a Personal Chair in Microelectronics. Since joining Southampton University, he has worked on polysilicon emitter bipolar transistors, high-speed bipolar and BiCMOS technologies, gate delay expressions for bipolar circuits, and the effects of fluorine in polysilicon emitters. His current research interests include SiGe heterojunction bipolar transistors, $\mathrm{SiGeC}$ and its device applications, and vertical MOS transistors for application in sub-100 nm CMOS technology. He has authored and co-authored over 120 papers in the technical literature, given invited papers on polysilicon emitters and SiGe heterojunction bipolar transistors, and has authored a book on bipolar transistors.
G. R. Booker received the Ph.D. degree in physics from the University of Cambridge, Cambridge, U.K., in 1966.

Since 1966, he has been Academic Staff Member of the Department of Materials, University of Oxford, Oxford, U.K. His main research interests have been in the structures of materials and their effects on the physical properties, especially in the field of semiconductor materials and devices. He has contributed significantly to the development, understanding, and application of a range of electron microscopical methods for materials assessment, and has authored more than 200 scientific papers.

Dr. Booker is a Fellow of the U.K. Institute of Physics 